\title{
A AMBIVALÊNCIA DO IDEALISMO CLASSICIZANTE NA POESIA PARNASIANA BRASILEIRA
}

Fernando C. Gil

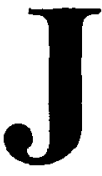

á faz algum tempo que a chamada poesia parnasiana tem sido crivada de epítetos os mais variados. ' Essas designações, via de regra sintomaticamente depreciativas, expressam o lugar que a crítica reservou à poesia parnasiana na história da literatura brasileira no século $X X$. Talvez não sem razão, os juízos se centram no "verso opulento e oco" de seus textos, na "cultura floreada, pomposa", ornamental, que emana da sua representação poética. Podemos sintetizar tal juizo crítico nas palavras de Antonio Candido, que diz que a poesia parnasiana define-se por ser uma literatura de permanência, isto é, uma poesia que "conserva e elabora traços desenvolvidos depois do Romantismo, sem dar origem a desenvolvimentos novos; e, o que é mais, parece acomodar-se com prazer nesta conservação". Para o crítico, se trataria de uma poesia "satisfeita, sem angústia formal, sem rebelião nem abismos. Sua única

* Universidade Federal do Paraná.

1 Uma primeira versão deste trabalho foi apresentada no V Congresso de Estudos Lingüísticos e Literários da Universidade Estadual de Feira de Santana, em maio de 2000. Ele é parte de pesquisa em andamento sobre poesia parnasiana e simbolista brasileira. 
GIL, F. C. A ambivalência do idealismo classicizante...

mágoa é não parecer de todo européia; seu esforço mais tenaz é conseguir pela cópia o equilíbrio e a harmonia, ou seja, o academicismo"."

É de se considerar que boa parte dessa crítica, ao expressar a sua profunda ressalva à poesia parnasiana, está explicitando os seus termos de análise tendo, no horizonte literário, as premissas do modernismo brasileiro. Isso significa dizer que o parnasianismo acaba surgindo, na história da literatura brasileira, quase sempre como a imagem negativa de um instante histórico de nossa formação poética. Nessa perspectiva histórico-crítica, o modernismo emerge como a imagem positiva, ao se supor que ele recupera e reinstala o sentido poético, até então esgotado e perdido em razão da intranscendência da literatura parnasiana e do vazio cultural do seu horizonte intelectual.

Dessas formulações, a meu ver, decorrem dois problemas relacionados que em parte esterilizam a postura crítica: de um lado, esse tipo de abordagem perde de vista os problemas específicos de um momento da literatura brasileira que tem a ver ainda com a dinâmica do sistema literário brasileiro no seu conjunto; de outro, se contenta em diagnosticar a ausência de "indagação vertical", a falta de "qualquer profundidade" poética tramada numa linguagem pseudo-requintada e pomposa, sem todavia se perguntar das razões de tal falta de profundidade ou das condições de produção, circulação e de recepção artísticas que definem tal estágio de nossa formação poética.

Não por acaso, nem mesmo por provocação, gostaria de fazer algumas observações sobre o que, com muita razão, tem sido considerado como o pior da produção poética do período. Trata-se das relações que a poesia parnasiana manteve com a convenção greco-latina, com o triunfo, como diz Brito Broca, que a Grécia teve no horizonte literário do parnasianismo e no nosso ambiente cultural. ${ }^{3}$ Vista sempre como uma manifestação explícita da literatura decorativa, ornamental da nossa belle époque, acredito entretanto que essa poesia diz muito dos impasses e das contradições em que se encontravam o poeta brasileiro e a sua literatura. Vejamos, então.

No plano das formas poéticas, o desejo de recuperar elementos da convenção cultural e literária greco-latina situa a poesia parnasiana ao lado da crença e da confiança do poder da palavra poética em enunciar o mundo. Este senso de domínio do objeto poético adquire forma e visibilidade na dicção solene e elevada do poema. A elevação do tom poético, entre outras coisas,

2 CANDIDO, Antonio. Literatura e sociedade. 5. ed. São Paulo: Nacional, 1976. p. 113.

3 BROCA, Brito. A vida literária no Brasil - 1900. 3. ed. Rio de Janeiro: José Olympio, 1975. p. 102. 
parece ser a evidência de que sujeito-lírico e objeto poético incorporam e dão expressão à representação de uma inteireza e de uma transparência poéticas que, centrada aparentemente antes no objeto do que no sujeito, acaba por dizer, como veremos mais adiante, muito mais do eu-lírico do que do objeto apreendido.

Os temas e os assuntos dessa poesia podem ser vários: a figuração de personagens do mundo clássico em poemas narrativos ("A tentação de Xenócrates", de Olavo Bilac); a descrição de uma cena histórica ou de um objeto cultural desse mundo (no primeiro caso, "Messalina", ainda de Olavo Bilac; no segundo, "Vaso grego", de Alberto Oliveira, e "Lendo a Ilíada", de Olavo Bilac); ou ainda a simples evocação desse mundo modelar e suas entidades ("Ode parnasiana", de Raimundo Correia).

A força enunciativa que a poesia parnasiana atribui para si no presente origina-se da capacidade do poeta em remeter-se ao passado, uma vez que residem lá as formas de expressões consagradas a serem seguidas. É este sentido que, por exemplo, toma a invocação feita por Francisca Júlia, quando diz em um dos sonetos de "Musa impassível":

Leva-me longe, ó Musa impassível e branca!

Longe, acima do mundo, imensidade em fora,

Onde, chamas lançando ao cortejo da aurora,

$\mathrm{O}$ áureo plaustro do sol nas nuvens solavanca.

Transporta-me de vez, numa ascensão ardente,

À deliciosa paz dos Olímpicos-Lares

Onde os deuses pagãos vivem eternamente,

E onde, num longo olhar, eu possa ver contigo

Passarem, através das brumas seculares,

Os Poetas e os Heróis do grande mundo antigo. ${ }^{4}$

Observe-se que o desejo do poeta é não somente o de ser transportado, mas o de que este transporte tenha também o sentido de uma viagem "acima do mundo", "imensidade em fora" "numa ascensão ardente". Dessa forma, num só golpe, o poeta empreende o seu ingresso ao passado e, ao mesmo tempo, esse

4 Apud ABDALA JÚNIOR, Benjamin. Antologia de poesia brasileira: realismo e parnasianismo. São Paulo: Ática, 1985, p. 56. 
GIL, F. C. A ambivalência do idealismo classicizante...

ingresso passa ainda a significar a retirada do poeta do mundo, na medida em que o "grande mundo antigo" está acima, está para além, digamos, do mundo de todos os mortais.

Situado nessa esfera superior, portanto fora da história e de suas tensões, o poeta acredita poder comungar da mesma dignidade emanada da tradição e também poder partilhar do valor universalizante com que ele compreende essa tradição. Comunhão e partilha essas nos são sugeridas no antológico poema "Vaso grego", de Alberto de Oliveira, que diz:

Esta de áureos relevos, trabalhada

De divas mãos, brilhante copa, um dia,

Já de aos deuses servir como cansada,

Vinda do Olimpo, a um novo deus servia.

Era o poeta de Teos que a suspendia

Então, e, ora repleta ora esvazada,

A taça amiga aos dedos seus tinia,

Toda de roxas pétalas colmada.

Depois... Mas o lavor da taça admira,

Toca-a, e do ouvido aproximando-a, às bordas

Finas hás de lhe ouvir, canora e doce,

Ignota voz, qual se da antiga lira

Fosse a encantada música das cordas,

Qual se essa voz de Anacreonte fosse. ${ }^{5}$

Este soneto parece, aparentemente, sintetizar em si o gesto ideal da criação parnasiana, com tudo aquilo que o próprio Alberto de Oliveira pedia à poesia de sua época no ensaio $O$ culto da forma na poesia brasileira: a "expressão perfeita", "a precisão vocabular", a "elevação e a distinção da linguagem" poética. ${ }^{6}$ No caso do poema mencionado, o esforço do poeta para pôr em prática tais princípios revela-se em vários planos. Tal esforço começa a indicar a sua presença no deslocamento da sintaxe linear com o objetivo de obter

5 Apud ABDALA JÚNIOR, p. 29.

6 OLIVEIRA, Alberto de. O culto da forma na poesia brasileira. In: COUTINHO, Afrânio. Caminhos do pensamento crítico. Rio de Janeiro: Pallas/Brasília: INL, 1980. v. 1. p. 594. 
um efeito rítmico de expressão o mais sóbrio e o menos prosaico possível. A esse ritmo se articula um léxico do qual se desprendem o refinamento e a distinção com que o objeto poético é representado, ao mesmo tempo em que tal refinamento e tal distinção são vistos como emanados da própria presença do objeto. Neste sentido, o modo de objetivar o objeto poético, que é dado sobretudo pela ativação do procedimento descritivo, subsume em seu processo o sujeito-lírico. $O$ que, no caso, não se trata, aos olhos do poeta parnasiano, de nenhum amesquinhamento de sua posição no mundo; pelo contrário, deixar falar o objeto pelo que esse supostamente contém e transmite de elevado e de transcendente é também um modo de circunscrever o artista numa esfera excelsa. "Em virtude do puro-vir-a-si-mesma da linguagem na condição de linguagem artística, através do esforço pela absoluta objetividade dela (da linguagem artística)", 7 para se usar os termos de Adorno, pode-se dizcr que o poeta executa c concebe o seu ideal - e portanto a si mesmo como artista através do aparato poético. No interior desse aparato poético e por meio dele, linguagem e objeto artísticos tomam formas próprias, autônomas com relação às outras esferas sociais e às linguagens que correspondem a essas esferas. Sob esta perspectiva, o poeta garante a sua sobrevida por meio da beleza que "vive a vida na arte". De outra parte, não se pode esquecer, como já se assinalou anteriormente, que essa beleza pede ainda a chancela e o prestígio da tradição, via adoção da convenção classicizante, no que essa sugere conter de valor universal e eterno.

Penso que não seria de todo equivocado afirmar que o poeta parnasiano procura, com esta atitude poética, resguardar, consciente ou inconscientemente, pouco importa, aquilo que Walter Benjamin chamou de valor de culto. A idéia benjaminiana de valor de culto liga-se ao caráter de autenticidade da obra de arte, à sua existência única, singular, irreprodutível. Como nota Benjamin, a autenticidade enraíza-se na tradição; e se por um lado essa tradiçāo é dinâmica e variável, por outro, tem a sua forma mais primitiva de expressão no culto, seja esse mágico ou religioso. Assim sendo, "o valor único da obra de arte 'autêntica' tem sempre um fundamento tcológico, por mais remoto que seja: ele pode ser reconhecido, como ritual secularizado, mesmo nas formas mais profanas do culto do Belo". 9

7 ADORNO, W. Lírica e sociedade. In: Os Pensadores. 2. ed. São Paulo: Abril Cultural, 1983. p. 199.

8 CANDIDO, Antonio. Na sala de aula. 3. ed. São Paulo: Ática, 1989. p. 67.

9 BENJAMIN, Walter. A obra de arte na era de sua reprodutibilidade técnica. Im: Magia 
No contexto capitalista das novas formas de produção e reprodução de som e de imagem que se instalam particularmente a partir da segunda metade do século XIX, e no qual essa noção aurática da obra de arte tende a desaparecer, ou a no mínimo entrar em crise, o poeta funda uma teologia da arte, a idéia da "arte pura", a noção da "arte pela arte". $\mathrm{O}$ artista busca criar uma esfera própria para a sua atividade e para a consecução dos seus objetivos artísticos, livre das tensões da história, de sua função social e das determinações objetivas do mundo. Voltarei a este ponto mais adiante.

Mas falando assim, pode parecer um disparate, um contra-senso crítico e também analítico pensar no caráter "autêntico" da poesia parnasiana, uma poesia, como já se disse, normalmente compreendida como "oca", "intranscendente" e "decorativa". Bem entendido, meu objetivo não é recuperar o espaço original, singular, transcendente da poesia parnasiana.

Meu objetivo é de outra ordem. Minha intenção seria a de ao menos tentar esboçar uma explicação mais consistente para a seguinte questão: quais as condições de produção artística, no Brasil do final do século XIX e no início do XX, que fazem com que se estiole boa parte da produção poética do período? $\mathrm{Ou}$ colocando o mesmo problema tendo em vista as observações até aqui formuladas: o que faz com que a poesia parnasiana situe-se num plano bastante insubstancial e intranscendente, quando todo o esforço com que ela se projetou no mundo é o de se fazer e ver-se elevada? Quem sabe, ainda poderíamos nos perguntar de outra maneira: sobre que condições está definida a noção de valor de culto na poesia parnasiana? Essa sacralização do espaço da poesia brasileira é expressão do quê no interior do processo de produção literária brasileira à época?

Para ao menos tentarmos esboçar uma resposta a esse problema, é preciso dizer que a presença da notação classicizante na poesia parnasiana move-se no terreno da ambigüidade. Não se trata aqui da poesia que elabora a ambigüidade como expressão dos impasses objetivos (e também ideológicos) do processo social, transfigurados e tensionados pela linguagem da poesia, ou seja, como formação poética que se engendra como crítica da civilização. A ambigüidade a que me refiro deve ser apreendida na dinâmica mesma do nosso sistema literário, nas contradições que configuram o seu modo de ser específico.

Vou tentar equacionar essa questão da seguinte forma: a linguagem da poesia parnasiana convertida em espaço sagrado, em valor de culto, não deixa de trazer embutido em si o seu elemento antitético, contrastante, que é a noção ainda benjaminiana de valor de exposição. ${ }^{10} \mathrm{~A}$ exponibilidade da poesia par-

e técnica, arte e politica. São Paulo: Brasiliense, 1985. p. 171. 
nasiana diz respeito ao que um estudioso do parnasianismo anotou muito bem como sendo a expressão daqueles "que concebem a poesia como o lugar da exibição pública, espécie de estátua que não apresenta nenhuma cicatriz, espécie de figuração exemplar, para consumo dos leitores, do ideal de vida". ${ }^{11}$ Estou sugerindo, com isso, que a poesia parnasiana configura-se, na sua relação com a notação classicizante, como uma espécie de cabeça de Jano, que ora parece olhar apenas para o seu interior, ora quer mostrar-se como objeto de exposição e de apreciação pública. $O$ modo como a poesia parnasiana dominou a cena literária brasileira, da década de 80 do século passado até os dois primeiros decênios deste, nos diz muito da forma exemplar e paradigmática como essa poesia pretendeu expor-se a público.

Esse jogo duplo, ao mesmo tempo de recuo e de exposição do poeta e da poesia, sintetiza em si o caráter ambíguo do que estou tentando descrever. Expor o valor sagrado e sacralizado da linguagem poética a público significa circunscrever a literatura - o artista e o seu objeto-numa posição heráldica, num campo bem demarcado cujos status e prestígio conferidos para si se mostram insuperáveis e inultrapassáveis face às outras ordens de coisas com que a poesia vai se defrontar na medida em ela também se faz objeto de exposição. Digamos então que há um desejo do poeta parnasiano em conceber o seu objeto e a sua atividade artísticos no plano do sublime, do elevado. Assim, o domínio da convenção classicizante e a empostação elevada com que a poesia se reveste é a expressão de uma consciência artística que quer fazer-se sentir superior. No grandioso e no incomensurável da materialidade da representação poética parnasiana, o poeta dá sentido e forma às figurações de relevância e de poder que sua consciência atribui a si e à sua função criativa.

A idéia de que a convenção classicizante circunscreve a poesia parnasiana numa experiência estética ambígua, oscilando entre o seu valor de culto e de exposição, talvez tome uma dimensão mais precisa se entendermos que ela surge e transita no interior de um sistema literário já formado, mas precariamente formado. Em outras palavras, numa cultura "defeituosa" e "falha" como a nossa, na qual "faltou - para se usar as palavras de um crítico da época - sempre o elemento transmissor, o mediador plástico do pensamento nacional, um povo suficientemente culto para interessar-se por esse pensamento, ou, ao menos, apto a se deixar influenciar por ele", 12 a convenção classicizante funciona como

10 BENJAMIN. p. 173.

11 FISCHER, Luís Augusto. Simbolistas \& Pamasianos. Continente Sul Sur, n. 8, p. 85, 1998. 
GIL, F. C. A ambivalência do idealismo classicizante...

um conteúdo mental compensatório para o artista. Nesse sistema literário de interlocução precariamente construída, a literatura insufla-se de importância, de relevância, de destaque. Este gesto autoconsagratório da poesia para consigo mesma é expressão de uma realidade deficitária aos olhos do artista, o qual procura criar, ao fim e ao cabo, estratégias discursivas, no interior da formação poética, que compensem a seus olhos e aos dos seus precários e rarefeitos leitores a sua situação não menos precária e instável no interior do sistema literário. Não deixa de resultar disso a expressão de uma autoconsciência artística que procura diferenciar-se, "porque o escrever - tanta perícia/ tanta requer/Que ofício tal... nem há notícia/ De outro qualquer".

Assim, se o poeta parnasiano deseja inscrever a sua experiência estética no plano do sagrado e do elevado, religando seu objeto a um valor de culto, não se pode deixar de assinalar um outro fator que atua no interior desse processo. Este fator diz respeito à profissionalização do escritor, ou seja, à possibilidade potencial que o escritor passa a ter de sobreviver do que escreve. $O$ novo horizonte profissional foi determinado pelas transformações técnicas, como já se mencionou rapidamente acima, ocorridas nas formas de produção, reprodução e circulação de imagem e de som, as quais vão se refletir sobremaneira no processo de industrialização da imprensa brasileira no período. $O$ jornal e o jornalismo não somente absorverão artistas e intelectuais em um mercado de trabalho mais especializado, permitindo sua relativa sobrevivência nessa função, como também redimensionarão a atuação do artista e da sua produção no interior do sistema literário. Nicolau Sevcenko, em Literatura como missão, anota essa relação entre literatura e ambiente social que vai se descortinando:

As transformações nas técnicas de comunicação, acompanhando e aprofundando as mudanças do modo de vida em todo o mundo, nesse curto espaço de tempo, abalaram definitivamente a posição até então ocupada pela literatura. A foto e o cinema tornaram dispensáveis e enfadonhos os longos comentários dos cronistas tradicionais. A transformação súbita dos cenários urbanos e rurais, os novos objetos, instrumentos, hábitos e rotinas estabelecidos num prazo surpreendentemente curto tornaram inade-

12 VERISSIMO, José. O que falta à nossa literatura. $m$ : José Verissimo: teoria, crítica e história da literatura. Rio de Janeiro: Livros Técnicos e Científicos: São Paulo: Ed. Universidade de São Paulo, 1977. p. 64-65.

13 BILAC, Olavo. Obra reunida. Rio de Janeiro: Nova Aguilar, 1997. p. 90. 
quadas e mesmo ultrapassadas as imagens literárias tradicionais. Ao mesmo tempo que entravavam a linguagem escrita com neologismos e adaptações apressadas, que, carentes da familiaridade e do polimento que só o longo trato artístico dá às palavras, impediam a pronta adaptação da literatura ao novo mundo, a não ser ao custo de assumir uma secura que a descaracterizava fortemente se contrastada com o seu passado. A adaptação custaria o preço de sua sacralidade. ${ }^{14}$

Um pouco mais adiante, $\mathrm{o}$ autor acrescenta:

[...] a concorrência do jornalismo desassossegou os literatos mais ciosos da sua seara. O jornalismo, impondo uma vigorosa padronização à linguagem e empregando praticamente todos os homens de letras em suas redaçōes, acabou necessariamente exercendo um efeito geral negativo sobre a criação artística. Tendendo ao sufocamento da originalidade dos autores e contribuindo em definitivo para o processo de banalização da linguagem literária, suas baixas remunerações exigiam ainda uma facúndia e prolixidade tal dos escritores, que impediam qualquer preocupação com o apuro da expressão ou do estilo. ${ }^{15}$

As formulações de Nicolau Sevcenko nos permitem compreender com mais precisão um dos aspectos fundamentais do que estou procurando demonstrar: o de que o idealismo classicizante é, ao mesmo tempo, expressão e resultado desse campo de tensão que define a poesia brasileira nesse momento. De um lado, ele contém e manifesta a idéia de que, num sistema literário precariamente formado e, ainda por cima, ameaçado pela banalização, vulgarização e achatamento da literatura decorrente de sua mercantilização $\mathrm{em}$ diferentes níveis, a poesia pretende resguardar o seu quantum satis de dignidade ao se fazer sacralizada e distante das contingências do mundo histórico concreto. De outro lado, a convenção classicizante não deixa de integrar um repertório de signos e imagens literárias e mentais que pede a sua chancela à dinâmica mesma desse

14 SEVCENKO, Nicolau. Literatura como missão. 3. ed. São Paulo: Brasiliense, 1989. p. 97.

15 SEVCENKO, p. 100. 
GIL, F. C. A ambivalência do idealismo classicizante...

circuito o qual, se num primeiro momento pode surgir como rebaixado aos olhos do artista, é o único que pode lhe dar e garantir reconhecimento e prestígio como artista.

Expressão-síntese dessa nova inserção do escritor na sociedade e de sua posição ambígua em face dela é o modo não menos contraditório como Olavo Bilac enuncia o problema ao falar do papel que sua geração cumpriu no campo literário:

Que fizemos nós? Fizemos isto: transformamos o que era então um passatempo, um divertimento, naquilo que é hoje uma profissão, um culto, um sacerdócio; estabelecemos uma preço para o nosso trabalho, porque fizemos desse trabalho uma necessidade primordial da vida moral e da civilização de nossa terra... $^{16}$

Observe-se que para o autor de Via-Láctea as noções de sacerdócio e culto mostram-se compatíveis com as de profissão e de valor mercantil com que essa profissão se investe ("estabelecemos um preço"). Mais ainda, a transformação "desse trabalho" em uma "necessidade primordial da vida moral e da civilização de nossa terra...", esse efeito magnânimo da função do escritor, neutraliza qualquer problema de má-consciência que a profissionalização $\mathrm{c}$ a mercantilização pudessem impor à sua arte. A tentativa de conjugar e harmonizar sacerdócio e profissionalismo - ou seja, de compatibilizar o incompatível permeia o percurso que a convenção classicizante faz no interior da formação poética, ao querer articular em si valor de culto e de exposição. Assim, inserida no mundo do trabalho e dependente cada vez mais dele, a palavra poética no parnasianismo todavia buscou o distanciamento desse mundo, quis não tomar conhecimento dele, ainda que, paradoxalmente, desejasse mostrar-se a público "como um rubim".

É neste sentido que o idealismo classicizante da poesia parnasiana, que se manifesta na forma do desejo do sublime, projeta-se como uma espécie de universo compensatório da consciência onipotente do poeta em face de uma realidade deficitária e da mercantilização da própria palavra. Neste movimento,

16 Apud GOLDSTEIN, Norma (Org.). Literatura comentada: Olavo Bilac. São Paulo: Abril, 1980. p. 4. 
GIL, F. C. A ambivalência do idealismo classicizante...

o esplendor com que o poeta percebe a sua função e a de seu objeto faz apenas silenciar os impasses com que a literatura da época se defronta. Nesse silêncio, o poeta parnasiano transforma a poesia em falsa consciência de si mesmo.

\section{RESUMO}

Este ensaio analisa a convenção clássica na poesia parnasiana. Sugere que a representação poética classicizante problematizaria os impasses $\mathrm{e}$ as contradições da poesia e do poeta no Brasil no final do século XIX. Do ponto de vista desse estudo, a poesia parnasiana conjuga paradoxalmente uma imagem sagrada da arte a um desejo de exibição pública de si mesma.

Palavras-chave: Poesia brasileira, poesia parnasiana, poesia e história.

\section{ABSTRACT}

This essay analises Classical convention in the Brazilian Parnassian poetry. The article suggests that the Classical poetic representation would question the impasses and contradictions of the poet in Brazil at end of XIX century. The subject of his study, the Parnassian poetry combines paradoxically a sacred image of the art with a desire of public exhibition of itself.

Keywords: Brazilian poetry, Parnassian poetry, poetry and history.

\section{REFERÊNCIAS BIBLIOGRÁFICAS}

ABDALA JÚNIOR, Benjamin (Org.). Antologia de poesia brasileira: realismo e parnasianismo. São Paulo: Ática, 1985, p. 56.

ADORNO, W. Os Pensadores. 2. ed. São Paulo: Abril Cultural, 1983, p. 199.

BENJAMIN, Walter. Magia e técnica, arte e política. São Paulo: Brasiliense, 1985.

BILAC, Olavo. Obra reunida. Rio de Janeiro: Nova Aguilar, 1997. 
GIL, F. C. A ambivalência do idealismo classicizante...

BROCA, Brito. A vida literário no Brasil: 1900. 3. ed. Rio de Janeiro: José Olympio, 1975.

CANDIDO, Antonio. Literatura e sociedade. 5. ed. São Paulo: Nacional, 1976. . Na sala de aula. 3. ed. São Paulo: Ática, 1989.

COUTINHO, Afrânio (Org.) Caminhos do pensamento crítico. Rio de Janeiro: Pallas/Brasília: INL, v. 1.

FISCHER, Luís Augusto. Simbolistas \& parnasianos. Continente Sul Sur, n. 8, 1998.

GOLDSTEIN, Norma (Org.) Literatura comentada: Olavo Bilac. São Paulo: Abril, 1980.

SEVCENKO, Nicolau. Literatura como missão. 3. ed. São Paulo: Brasiliense, 1989.

VERÍSSIMO, José. José Veríssimo: teoria, crítica e história da literatura. Rio de Janeiro: Livros Técnicos e Científicos/São Paulo: Ed. da Universidade de São Paulo, 1977. 